\title{
Vowel Fission in Jaqaru
}

\section{Rachel Walker, University of Southern California}

In Jaqaru (Aymaran, Peru), stressed vowels show copy harmony with a following suffix vowel, as in (1). The vowel inventory for Jaqaru consists of /i, a, u/. The data owe to Cerrón-Palomino (2000 and personal communication).
[i] t timí-ni 'with belly' paki-fí-fi 'to break oneself' was-mí- $K \mathbf{i}$ 'hey, be careful'
[a] nuná-ja 'to cause to rinse'

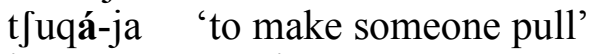
[u] im-kú-fu 'sewing' ajKú-ru 'to overflow'

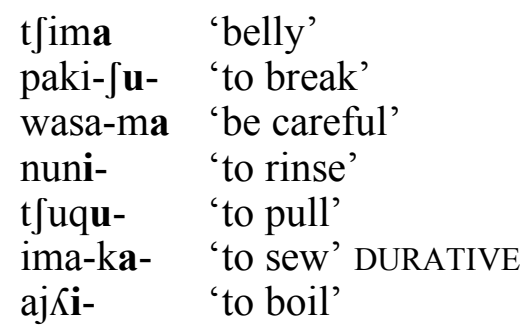

This paper deals with the interaction of stressed vowel copy harmony and a copy harmony involving an 'epenthetic' vowel, i.e. a vowel that appears to be inserted. Stress in Jaqaru is usually penultimate, but it is antepenultimate in loans that were consonant-final and stressed on the penult in the donor language. A final vowel is added to avoid a consonant-final root. The added vowel usually copies the preceding one, as in (2), yielding 'epenthesis' copy harmony. Note that because there is no suffix in these forms, stressed vowel copy harmony is not expected.
[i] mártisi < martes (Spanish) qántsi i $<$ qantsif (Quechua)
'Tuesday'
[a] húpasa $<$ uvas (Spanish) qáKaja < qaKaj (Quechua)
'seven'
[u] áxusu
$<$ ajos (Spanish)
ríluxu $<$ reloj (Spanish)
'grapes'
'to begin'
'garlic'
'watch'

When these loans are suffixed, stress shifts to the penult. Base contraction optionally occurs when the word would exceed three syllables. In noncontracted forms, if the trisyllabic base of affixation is retained, the stressed vowel shows harmony with the suffix, as in (3a), like the forms in (1). A contracted variant is also available with what seems to be deletion of the second vowel, as in (3b). Here, the final vowel of the base displays the quality of the original vowel in the root-final syllable rather than harmonizing to the suffix.
a. Noncontracted form axusí-ni
b. Contracted form
riluxí-ni
axsú-ni
rilxú-ni
'garlic' POSS.
'watch' POSS.

Contracted forms present a challenge for phonological theory. First, they seem to present a counterbleeding opacity: epenthesis and harmony with the second root vowel must precede vowel deletion (4a); otherwise, deletion bleeds 'epenthesis' copy harmony with the appropriate vowel (4b). Second, even with this complexity in the analysis, blocking of stressed vowel copy harmony with the suffix in the contracted form only is not predicted.
(4) a

Underlying representation
Epenthesis
Harmony with root vowel
Deletion
/axus-ni/
axusV-ni
b. Underlying representation
/axus-ni/
Epenthesis
axusu-ni
Deletion
axsu-ni
Harmony with root vowel
axusV-ni
axsV-ni
[axsú-ni]
Surface representation
axsa-ni
*[axsá-ni]

This paper proposes an alternative solution using noncanonical correspondence in the form of vowel fission and consonant-vowel (CV) metathesis, standing in place of epenthesis and deletion processes, respectively. As we will see, this approach eliminates a treatment employing derivational opacity and it offers an integrated explanation of the blocking of harmony from the suffix in contracted forms.

By way of background, I deal first with the stressed vowel copy harmony in (1). Harmony with a weak trigger and strong target have been analyzed as driven by licensing constraints 
which penalize weak structure that is not affiliated with a prominent position (Walker 2005). Cerrón-Palomino López (2003) analyzes Jaqaru's stressed vowel copy harmony using a constraint that requires features of post-tonic vowels to be affiliated with a stressed syllable (5). (Constraint specifics differ to some extent from that of Cerrón-Palomino López, but achieve similar effect.) [V-FEATURE] is used to collapse constraints for individual vowel quality features.

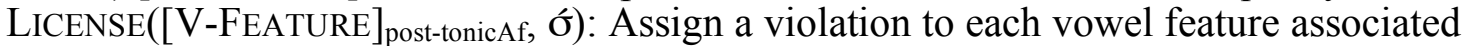
with a post-tonic suffix vowel that lacks an association to the stressed syllable.

Cerrón-Palomino López ascribes control of harmony by the post-tonic vowel to a faithfulness constraint for word-final syllables. In the ranking that he posits, the word-final faithfulness constraint dominates its counterpart for stressed syllables (Beckman 1998), as does the licensing constraint: IDENT- $\sigma_{\text {Final }}(\mathrm{V} \text {-FEATURE), LiCENSE([V-FEATURE] }]_{\text {post-tonicAf, }}$ ó) >> IDENT-ó(VFEATURE). The ranking is illustrated in (6). For the input /nuni-ja/, it drives regressive harmony from the suffix to the stressed vowel, as in (6a), in order to satisy the licensing constraint and word-final faithfulness. Candidate (6b), without harmony, violates the licensing constraint, and candidate (6c), with progressive harmony from the stressed syllable, violates faithfulness for the final syllable. For simplicity, a single "*" is shown in each column for any vowel that violates licensing or an IDENT(V-FEATURE) constraint, but this does not alter the outcome.

(6) Stressed vowel copy harmony in native words

\begin{tabular}{|c||c:c|c|}
\hline$/$ nuni-ja/ & LICENSE([V-F $]_{\text {post-tonicAf, ó) }}$ & IDENT- $\sigma_{\text {Final }}(\mathrm{V}-\mathrm{F})$ & IDENT-ó(V-F) \\
\hline \hline a. nuná-ja & & & $*$ \\
\hline b. nuní-ja & $* !$ & & \\
\hline c. nuní-ji & & $* !$ & \\
\hline
\end{tabular}

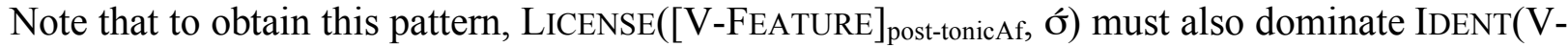
FEATURE), which is not position sensitive (this constraint is not shown in (6)).

Returning to the interaction with 'epenthetic' vowels in loans, the key generalizations in the relevant forms are that i) the stressed epenthetic vowel harmonizes with the following suffix vowel when the base is not contracted, and ii) the 'epenthetic' vowel resists harmony with the suffix vowel when the root base is contracted, and in that case it is realized with the quality of the apparently deleted vowel.

This paper analyzes the apparent epenthesis as the result of vowel fission, where a vowel has multiple correspondents in the output (Struijke 2000). It is proposed that fission is driven by $\operatorname{ANCHOR}\left(\operatorname{Root}_{\mathrm{O}}, \mathrm{V}_{\mathrm{I}}, \mathrm{R}\right)$, which requires any element at the right edge of a root in the output to have a correspondent with some vowel in the input (extending the ANCHOR formalism of McCarthy 2003). This constraint has wide-ranging utility in Aymaran languages, where roots may not end in a consonant in general. The final vowel must actually be an exponent of the root in order to satisfy the ANCHOR constraint, which is achieved by fission but not epenthesis. The fission structure is shown in (7a): / $\mathrm{u} /$ has correspondents in the last two root syllables. Apparent epenthesis, harmony, and deletion in contracted forms are analyzed as CV metathesis, as in (7b). Here $/ \mathrm{u} /$ occurs only in root-final position in the output. Under this approach, neither deletion nor epenthesis actually occur and 'epenthesis copy harmony' is the product of noncanonical correspondence configurations, i.e. ones involving fission or metathesis. In other words, the 'epenthetic' vowel shows copy harmony because it is in correspondence with the second vowel of the root in the input rather than assimilating with another vowel in the output.

(7)

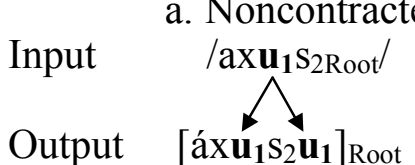

b. Contracted affixed form: CV metathesis

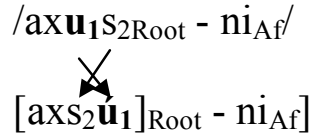

I will consider the derivation of each of these structures in turn, starting with fission in noncontracted forms. INTEGRITY-IO penalizes mappings in which an element of the input has 
multiple correspondents in the output (McCarthy \& Prince 1995). Vowel fission in (7a) necessitates the ranking ANCHOR-R >> INTEGRITY. Struijke has argued that fission structures motivate an existential statement of faithfulness. Relevant here is $\exists$-LINEARITY, formalized in (8) (adapted from Struijke 2000). $\exists$-LINEARITY will also dominate INTEGRITY, as illustrated in (9).

(8) ᄏ-LINEARITY-IO: "If a segment precedes another segment in the input, some output correspondent of the first segment precedes some output correspondent of the second segment."

In the winning candidate, (9a), vowel fission produces the effect of copy epenthesis. This violates INTEGRITY. The altenative candidate in (9b) has a consonant-final root, which is ruled out by ANCHOR-R, and (9c), with CV metathesis, is prevented by $\exists$-LINEARITY.

\begin{tabular}{|c||c:c|c|}
\hline$/ \mathrm{axu}_{1} \mathrm{~s}_{\mathrm{R} t} /$ & ANCHOR-R & ヨ-LINEARITY & INTEGRITY \\
\hline a. $\left[\mathrm{áxu}_{1} \mathrm{~s}_{2} \mathrm{u}_{1}\right]_{\mathrm{Rt}}$ & & & $*$ \\
\hline b. $\left[\mathrm{áxu}_{1} \mathrm{~s}_{2}\right]_{\mathrm{Rt}}$ & $* !$ & & \\
\hline c. $\left[\mathrm{a} \mathrm{as}_{2} \mathrm{u}_{1}\right]_{\mathrm{Rt}}$ & & $* !$ & \\
\hline
\end{tabular}

I turn now to contracted forms. I use $*[\sigma \sigma \sigma \sigma]_{\omega}$ as a cover constraint for the constraint(s) that serve to prevent words that exceed three syllables. Variable ranking of $*[\sigma \sigma \sigma \sigma]_{\omega}$ with respect to $\exists$-LINEARITY will obtain the optional contraction of words over three syllables, seen in (3). When $*[\sigma \sigma \sigma \sigma]_{\omega}$ is ranked sufficiently high to drive contraction, it dominates $\exists$-LINEARITY to produce metathesis. ANCHOR-R must also dominate J-LINEARITY. The resulting hierarchy is shown in (10). In this instance, the vowel fission outcome in $(10 \mathrm{~b})$, is ruled out by $*[\sigma \sigma \sigma \sigma]_{\omega}$. Another fission candidate, $\left[\left[\mathrm{axu}_{1} \mathrm{~s}_{2} \hat{1}_{1}\right]_{\mathrm{Rt}}-\mathrm{ni}_{\mathrm{Af}}\right]$, where the root-final vowel harmonizes with the suffix, would meet with the same fate. ANCHOR-R again serves to prevent a form with a consonant-final root, in (10c). The winner, in (10a), shows CV metathesis, violating lower-ranked $\exists$-LINEARITY.

(10) CV metathesis under base contraction

\begin{tabular}{|c||c:c|c|c|}
\hline$/ \mathrm{axu}_{1} \mathrm{~s}_{2 \mathrm{Rt}}-\mathrm{ni}_{\mathrm{Af}} /$ & $*[\sigma \sigma \sigma \sigma]_{\omega}$ & ANCHOR-R & ヨ-LINEARITY & INTEGRITY \\
\hline a. $\left[\left[\mathrm{axs}_{2} \mathrm{u}_{1}\right]_{\mathrm{Rt}}-\mathrm{ni} \mathrm{i}_{\mathrm{Af}}\right]$ & & & $*$ & \\
\hline b. $\left[\left[\mathrm{axu}_{1} \mathrm{~s}_{2} \mathrm{u}_{1}\right]_{\mathrm{Rt}}-\mathrm{ni} \mathrm{if}_{\mathrm{Af}}\right]$ & $* !$ & & & $*$ \\
\hline c. $\left[\left[\mathrm{axú}_{1} \mathrm{~s}_{2}\right]_{\mathrm{Rt}}-\mathrm{ni}_{\mathrm{Af}}\right]$ & & $* !$ & & \\
\hline
\end{tabular}

Recall that when the base is contracted, the vowel features of a suffix are not licensed, and only then; compare [axusí-ni] [axsú-ni] 'garlic' POSS. Put another way, when the root is contracted, harmony from the suffix is blocked. This is captured using an existential identity constraint (Struijke 2000) indexed to roots in the loan stratum 'L' of the lexicon (e.g. Pater 2009). $\exists$-IDENT- $\mathrm{IO}_{\mathrm{L}}(\mathrm{F})$ requires that if an input segment of a loan-stratum root has correspondent output segment(s), there is some output correspondent of that input segment with an identical specification for $[\mathrm{F}]$. $\exists$-IDENT(V-FEATURE) $\mathrm{L}$ outranks the LICENSE constraint. This draws the distinction in behavior of contracted and noncontracted forms as follows. In noncontracted affixed forms a vowel undergoes fission and has two output correspondents. $\exists$-IDENT is satisfied provided at least one of those correspondents is identical to the input vowel. This makes one of the two correspondents of a fissioned vowel receptive to a phonological process that alters it, allowing these forms to present stressed vowel copy harmony. On the other hand, in contracted forms, there is only a single output correspondent for each input vowel. This makes each vowel resist undergoing harmony, since that would entail violation of $\exists$-IDENT, and as a consequence, stressed vowel copy harmony is blocked.

Proceeding to further ranking details, when a suffix vowel's features do not achieve satisfaction of licensing by triggering harmony in the stressed vowel, it maps faithfully in final position rather than undergoing harmony to the stressed vowel. This indicates that word-final IDENT(V-FEATURE) dominates the licensing constraint to protect the suffix vowel. LICENSE([VFEATURE], ó) dominates the general IDENT(V-FEATURE) constraint to guarantee that harmony occurs when a loan root is not involved. (IDENT(V-FEATURE) could be characterized as an $\exists$ - 
IDENT constraint, but because there is only a single output correspondent for each vowel in native forms, it would not affect the outcome.) Since $\exists$-IDENT(V-FEATURE)L is indexed to loans, it will not interfere with regular copy harmony in stressed vowels in native roots, as in (6).

The tableau in (11) shows the workings of the constraints in question. Both (11i) and (11ii) have the same input, with a loan-stratum root and a suffix. In (11i) the input maps to an output with a noncontracted root; in (11ii) it maps to the variant with a contracted root. Both are wellformed in the language. What determines the choice of variant is a separate issue, not under focus here. In (11i), the second root vowel in the input has two correspondents in the optimal output (11ia). This allows the root-final vowel to undergo licensing-driven harmony without incurring a violation of $\exists-\operatorname{IDENT}(\mathrm{V}-\mathrm{F})_{\mathrm{L}}$, because some correspondent of the root vowel exists in the output that is faithful to its features in the input. In (11ii), the alternate form where the second root vowel has only one output correspondent is considered. In the winning candidate in (11iia), harmony from the word-final vowel does not operate. $\exists$-IDENT(V-F)L blocks harmony (11iib). In (11iic), harmony operates from root to suffix, which is prevented by faith to the final syllable.

(11) Harmony and lack of harmony in loans with consonant-final roots

\begin{tabular}{|c|c|c|c|c|c|}
\hline & $/ \operatorname{axu}_{1} \mathrm{~s}_{2 \mathrm{~L}}-\mathrm{ni} /$ & $\begin{array}{c}\text { ב-IDENT } \\
(\mathrm{V}-\mathrm{F})_{\mathrm{L}}\end{array}$ & $\begin{array}{c}\text { IDENT- } \\
\sigma_{\text {Final }}(\mathrm{V}-\mathrm{F})\end{array}$ & $\begin{array}{c}\text { LICENSE } \\
\left([\mathrm{V}-\mathrm{F}]_{\text {post-tonicAf }}, \sigma o\right)\end{array}$ & $\begin{array}{l}\text { IDENT } \\
(\mathrm{V}-\mathrm{F})\end{array}$ \\
\hline \multirow[t]{2}{*}{ i. Noncontracted } & a. $\mathrm{axu}_{1} \mathrm{~s}_{2} \hat{1}_{1}-\mathrm{ni}$ & & & & $*$ \\
\hline & b. $\operatorname{axu}_{1} \mathrm{~s}_{2} \mathrm{u}_{1}-\mathrm{ni}$ & & & $* !$ & \\
\hline \multirow[t]{3}{*}{ ii. Contracted } & a. $\operatorname{axs}_{2} u_{1}-n i$ & & & $*$ & \\
\hline & b. $\operatorname{axs}_{2} 1_{1}$-ni & $* !$ & & & $*$ \\
\hline & c. $\operatorname{axs}_{2} \mathrm{u}_{1}-\mathrm{nu}$ & & $* !$ & & $*$ \\
\hline
\end{tabular}

To sum up, the noncanonical correspondence analysis obtains the copy harmonies of Jaqaru and their interaction without certain problems of the rule-ordering approach. It does not invoke counterbleeding opacity (or an equivalent measure) and it predicts the blocking of stressed vowel copy harmony in contracted forms. The analysis posits two distinct drives for copy harmony phemonena: stressed vowel copy harmony involves licensing of features in a prominent position, and 'epenthesis' copy harmony results from noncanonical correspondence with an input root vowel, involving either vowel fission or CV metathesis. Existential faithfulness plays a pivotal role, offering an straightforward account for why stressed vowel copy harmony is blocked in contracted forms but not in noncontracted ones. The explanation afforded by this approach thus provides support for the existence of noncanonical correspondence scenarios and evidence that existential quantification of faithfulness is critical in mappings with multiple correspondence.

\section{References:}

Beckman, Jill. 1998. Positional Faithfulness. PhD dissertation, University of Massachusetts, Amherst. [http://roa.rutgers.edu/view.php3?id=246]

Cerrón-Palomino, Rodolfo. 2000. Lingüística Aimara. Cuzco: Bartolomé de Las Casas.

Cerrón-Palomino López, Alvaro. 2003. A case of weak triggers: Vowel harmony in Jaqaru. Ms., University of Southern California.

McCarthy, John. 2003. OT constraints are categorical. Phonology 20, 75-138.

McCarthy, John \& Alan Prince. 1995. Faithfulness and reduplicative identity. In Jill Beckman, Laura Walsh-Dickey \& Suzanne Urbanczyk, eds. UMOP: Papers in Optimality Theory, 249384. Amherst: GLSA. [http://roa.rutgers.edu/view.php3?id=568]

Pater, Joe. 2009. Morpheme-specific phonology: Constraint indexation and inconsistency resolution. In Steve Parker, ed., Phonological Argumentation: Essays on Evidence and Motivation, pp, 123-154. London: Equinox.

Struijke, Caro. 2000. Existential Faithfulness: A Study of Reduplicative TETU, Feature Movement, and Dissimilation. PhD dissertation, University of Maryland.

Walker, Rachel. 2005. Weak triggers in vowel harmony. NLLT 23, 917-989. 